archives-ouvertes

\title{
Potentially inappropriate prescription of antidepressants in old people: characteristics, associated factors, and impact on mortality
}

Anne Hiance-Delahaye, Florence Muller de Schongor, Laurent Lechowski, Laurent Teillet, Jean-Jacques Arvieu, Jean-Marie Robine, Joël Ankri, Marie Herr, Florence Muller De Schongor, Marie Robine, et al.

\section{To cite this version:}

Anne Hiance-Delahaye, Florence Muller de Schongor, Laurent Lechowski, Laurent Teillet, JeanJacques Arvieu, et al.. Potentially inappropriate prescription of antidepressants in old people: characteristics, associated factors, and impact on mortality. International Psychogeriatrics, Cambridge University Press (CUP), 2017, pp.1 - 12. <10.1017/S1041610217002290>. <inserm-01764264>

\section{HAL Id: inserm-01764264 http://www.hal.inserm.fr/inserm-01764264}

Submitted on 11 Apr 2018

HAL is a multi-disciplinary open access archive for the deposit and dissemination of scientific research documents, whether they are published or not. The documents may come from teaching and research institutions in France or abroad, or from public or private research centers.
L'archive ouverte pluridisciplinaire HAL, est destinée au dépôt et à la diffusion de documents scientifiques de niveau recherche, publiés ou non, émanant des établissements d'enseignement et de recherche français ou étrangers, des laboratoires publics ou privés. 
Potentially inappropriate prescription of antidepressants in old people: characteristics, associated factors, and impact on mortality

Anne Hiance-Delahaye ${ }^{(1,2,3,4)}$, Florence Muller de Schongor ${ }^{(1)}$, Laurent Lechowski ${ }^{(1,4)}$, Laurent Teillet ${ }^{(1,4)}$, JeanJacques Arvieu $^{(5)}$, Jean-Marie Robine ${ }^{(6,7)}$, Joël Ankri ${ }^{(2,3,5)}$, Marie Herr ${ }^{(2,3,5)}$

(1) Service de Gériatrie, Hôpital Sainte Perine, HUPIFO, AP-HP, Paris, France

(2) INSERM, U1168, VIMA: Aging and Chronic diseases. Epidemiological and Public Health approaches, Villejuif, F-94807, France

(3) Univ Versailles St-Quentin-en-Yvelines, UMR-S 1168, F-78180, Montigny le Bretonneux, France

(4) Univ Versailles St-Quentin-en-Yvelines, F-78180, Montigny le Bretonneux, France

(5) Département Hospitalier d'Epidémiologie et de Santé Publique, Hôpital Sainte Périne, APHP, Paris, France

(6) AG2R La Mondiale, Direction des Etudes, Prévoyance Individuelle et IARD, Paris, France

(7) INSERM U988 et U1198, EPHE, Paris \& Montpellier, France

Correspondence : Anne Hiance-Delahaye, Service de Gériatrie, 11 rue Chardon Lagache, 75016, Paris, France, Tel : +33 (0) 1449631 31, e-mail: anne.delahaye@aphp.spr.fr 


\begin{abstract}
Background: The increasing use of antidepressants (ADs) has raised concerns about their inappropriate use in old people. Objective: To examine the prevalence of potentially inappropriate prescriptions (PIPs) of ADs, their associated factors, and their impact on mortality in a sample of old people in France. Methods: The analysis used data from the SIPAF study, a cross-sectional study consisting of 2350 people aged $\geq 70$ years. Trained nurses interviewed participants at home between 2008 and 2010. Information was collected concerning sociodemographic and health characteristics, including medication use. The study population consisted of the 318 AD users from the SIPAF study (13.5\%). PIP of ADs was defined according to national and international criteria. Factors associated with PIP of ADs were assessed using a multivariate logistic regression model. The influence of PIP of ADs on mortality was assessed using a Cox model (median follow up 2.8 years). Results: Among the SIPAF study, $71 \%$ of $A D$ users were female and the mean age was $84 \pm 7$ years. Selective serotonin reuptake inhibitors (SSRIs) were the most prescribed ADs (19.8\%). We found PIP of ADs in $36.8 \%$ of the study population, mainly the co-prescription of diuretics with SSRIs (17.6\%) and the prescription of tricyclics (12.9\%). PIP of ADs was associated with polypharmacy ( $\mathrm{aOR}_{5-9}$ drugs $2.61,95 \%$ CI 1.11-6.16 and aOR $\geq 10$ drugs $2.69,95 \%$ CI 1.06-6.87) and comorbidity ( $\mathrm{aOR}_{3-4 \text { chronic diseases }} 2.59,95 \% \mathrm{CI} 1.04-6.44$ and $\mathrm{aOR}_{\geq 5 \text { chronic diseases }} 2.33,95 \% \mathrm{CI} 0.94-$ 5.79), and increased the risk of mortality during follow-up (aHR 2.30, 95\%CI 1.28-4.12). Conclusion: This study shows that more than one third of AD prescriptions may be inappropriate in old people. PIP of ADs was related to polypharmacy and comorbidity and increased mortality among AD users.
\end{abstract}

Keywords: Antidepressants, Adverse Events, Community care, Epidemiology. 


\section{Introduction}

Depression is one of the most frequent mental disorders in older adults and is a serious public health problem. The prevalence of depression after 75 years of age is estimated to be $7.2 \%$ (95\% CI 4.4-10.6\%) for major depression and 17.1\% (95\% CI 9.7-26.1\%) for depressive disorders (Luppa et al., 2012). Late-life depression is associated with disability and risk of death, independently of lifestyle and socioeconomic factors (Diniz et al., 2014).

Antidepressants (ADs) may effectively treat this invalidating illness in older people, with a range of therapeutic options including second generation ADs such as selective serotonin reuptake inhibitors (SSRIs) and serotoninnorepinephrine reuptake inhibitors (SNRIs) (Girardi et al., 2009; Kok and Reynolds, 2017). Their use has substantially increased during the last decades, especially SSRIs (Noordam et al., 2015). An American study reported that percentage of community-dwelling people aged $\geq 65$ years receiving ADs increased from $9.8 \%$ in $1996(\mathrm{n}=2,349)$ to $13.7 \%$ in $2005(\mathrm{n}=3,474)$ (Olfson and Marcus, 2009). A population-based study conducted in Australia estimated that the use of ADs increased by 41\% between 2002 and 2007 and that people aged 90-94 years were the largest consumers (Hollingworth et al., 2011). In Europe, the use of ADs doubled between 1993 and 2002 (Knapp, Martin et al., 2006), especially in nursing homes (Ruths et al., 2013).

The increasing use of $\mathrm{AD}$ can be explained by new indications (e.g. for SSRI: generalized anxiety disorder, panic, obsessive compulsive disorder, and post-traumatic stress disorder) (Raymond et al., 2007), increasing duration of treatment (Moore et al., 2009) and increased prescription of ADs by non-psychiatrist physicians (Mojtabai and Olfson, 2011).

Extensive use of ADs in old people has raised concerns about misuse and a subsequent increase in the risk of drug interactions and adverse events, such as osteoporosis and osteopenia, bleeding, hypertension or orthostatic hypotension, arrhythmia, and falls (Diniz and Reynolds, 2014). Older adults are likely to have altered drug metabolism and clearance, co-existing physical disorders, sensory deficits or other disabilities that call for caution when prescribing ADs (Kennedy and Marcus, 2005). An American study (Wang et al., 2005) revealed that among 12,130 new AD users aged $\geq 65$ years, $43 \%$ received suboptimal treatment, because of the use of anticholinergic drugs, excessively high or low daily dosages, short duration therapy or inadequate follow-up. A cross-sectional study in France showed that ADs represented $28.4 \%$ of the potentially inappropriate use of psychotropic drugs according to the 2003 Beers list (Prudent et al., 2008). 
Potentially inappropriate prescribing (PIP) in old people has become a major healthcare concern because of its association with adverse drug events, hospitalizations, and use of healthcare resources (Mort and Aparasu, 2000). Specific studies concerning PIP of ADs are currently limited to nursing-home residents (Bourgeois et al., 2012; Hanlon et al., 2011).

The main objective of this study was to describe the prevalence of and factors associated with PIP of ADs in a sample of people aged $\geq 70$ years in France. The secondary objective was to assess the impact of PIP of ADs on mortality.

\section{Methods}

\section{Study population}

This is a secondary analysis of the data from the SIPAF study, a cross-sectional study carried out to characterize health and functional independence among people $\geq 70$ years. The study population was composed of the 318 AD users included in the SIPAF study (13.5\%). Participants in the SIPAF study were selected at random among recipients of a supplementary pension fund (AG2R La Mondiale, Paris, France), with over-representation of the oldest-old. Recruitment took place from 2008 to 2010 in all regions of mainland France. The participation rate was $18.9 \%$ (details about participation are given elsewhere) (Herr et al., 2014). Information was collected at home by trained nurses. In $16.6 \%$ of cases, a close relative attended the interview to confirm or complete the answers of the participants. The information concerning deaths among the study population was provided by AG2R La Mondiale, with follow-up ending June 5, 2012 (median follow-up 2.8 years). Participants gave their written informed consent and the research protocol was approved by an independent ethics committee (permission n_060316).

\section{Data collection and geriatric assessment}

The following information about socio-demographic characteristics and general health was collected: age, gender, marital status, level of education, higher level of occupation between husband and wife, drinking and smoking habits, self-rating of health relative to people of the same age, and hospitalizations in the prior six months. Participants reporting chronic diseases were asked to identify their problem(s) among the list of 14 chronic diseases used to monitor population health by the European Commission (Robine et al., 2003), including chronic anxiety/depression. The number of years with depressive and/or anxiety symptoms was assessed by 
asking people who reported chronic anxiety and/or depression: "How long have you been suffering from this condition?" (variable expressed in tertiles). In addition to self-reported chronic diseases, we identified cardiovascular fragility by the prescription of at least one of the following drugs: antiarrhythmic or digitalic or coronary vasodilator drugs.

Geriatric problems were specifically investigated. Nutritional impairment was defined by a body mass index of $21 \mathrm{~kg} / \mathrm{m}^{2}$ or lower and/or unintentional weight loss of $10 \%$ of body weight during the prior six months. Questions about physical and sensory limitations dealt with the ability to see newspaper print clearly and to see the face of someone $4 \mathrm{~m}$ away, and to distinctly hear what is said in a conversation with another person. Impaired mobility was defined as difficulty walking more than 500 meters and/or difficulty walking up and down one floor of stairs. Social isolation was defined by lack of support with practical features (when bedridden or when needing to be accompanied to a medical appointment or when needing help to prepare meals) and/or emotional features (when needing to talk or when needing advice or affection). Assessment of activity restrictions examined six activities of daily living according to Katz et al (Katz et al., 1963), i.e. "bathing, dressing, toileting, transferring, continence, and feeding", as well as instrumental activities of daily living (IADL) (Lawton and Brody, 1969) such as food preparation, the ability to use a phone, housekeeping, shopping and the ability to manage one's finances. Homebound status was defined as the incapacity to leave home without help. Depression was suspected in participants with a score $>5$ on the 15 -item Geriatric Depression Scale (Yesavage et al., 1982). Cognitive impairment was defined as a score $\leq 26$ on the Mini-Mental State Examination (Folstein and McHugh, 1975) and/or prescription of an anti-Alzheimer drug (Folstein et al., 1975).

\section{Medications}

Medications taken by the participants were assessed by asking the participants about their treatments and information was completed by reviewing the prescriptions participants had at home. The question was formulated as follows: "What medications are you currently taking? Could you show me your last prescriptions please?" Participants were invited to indicate whether they did not take some of the drugs prescribed to reduce the gap between drugs prescribed and those actually taken. Drugs were coded using the Anatomical Therapeutic Chemical Classification (ATC) System. Polypharmacy was defined as five drugs or more and excessive polypharmacy as 10 drugs or more. ADs were identified by the codes N06AA (tricyclic antidepressants - TCAs), N06AB (SSRIs), N06AG (monoamine oxidase inhibitors - MAOIs), and N06AX (SNRIs and other ADs, namely mianserin, tianeptine, and mirtazapine). 
PIP of ADs was defined according to the 2015 Beers list (American Geriatrics Society 2015 Beers Criteria Update Expert Panel, 2015), Laroche list (Laroche et al., 2007) and STOPP criteria v2 (O’Mahony et al., 2015). We also took into account French guidelines (ANSM, Agence Nationale de Sécurité du Médicament) published in 2006, Canadian guidelines from "Canadian Network for Mood and Anxiety Treatments" (CANMAT), and English guidelines from the "National Institute for Health and Clinical Excellence" (NICE), both published in 2009. The entire set of PIP of AD retrieved from these sources is shown in Table 1.

\section{Statistical analysis}

Descriptive statistics present the characteristics of the study population and $\mathrm{AD}$ treatments. Categorical variables are described with percentages and continuous variables with the mean $+/$ - standard deviation (SD). Bivariate and multivariate analyses were performed to identify the factors related to PIP of ADs among AD users. Variables associated with a $\mathrm{p}<0.20$ in bivariate analysis as well as age and gender were introduced into the multivariate analysis. The multivariate analysis used a logistic regression model. The final model was obtained using backward stepwise analysis ( $\mathrm{p}$ value for removal $>0.10$ ). The results are presented with odds ratios $(\mathrm{OR})$ and 95\% confidence intervals (CI). The effect of PIP of ADs on mortality was assessed using a Cox proportional hazard model. The Schoenfeld test showed that there was no evidence against the proportional Hazard assumption $(\mathrm{p}=0.142)$. Results are presented using Hazard Ratios (HR) and 95\% CI. Statistical analyses were performed using STATA $^{\circledR}$ software, version 13.0 (Stata Corp., College Station, TX).

\section{Results}

\section{Study population}

Among the $318 \mathrm{AD}$ users included in this study, $71 \%$ were female and mean age was $84 \pm 7$ years. We observed excessive polypharmacy (10 drugs or more) in $29.3 \%$ of the study population $(\mathrm{n}=93)$. Socio-demographic and health characteristics of the study population are described in Table 2.

\section{AD use}

AD use is described in Table 3. SSRIs were the most prescribed ADs, especially paroxetine (19.8\%), followed by escitalopram (9.4\%) and citalopram (9.4\%). Venlafaxine was the most prescribed SNRIs (10.7\%). TCAs were 
prescribed in $12.9 \%$ of the study population, amitriptyline in most cases. "Other antidepressants", such as mianserin were prescribed in $25.5 \%$ of the study population.

At least one PIP of ADs was identified for 117 AD users (36.8\%). The prevalence of the different PIP of ADs is shown in Table 1. Concomitant prescription of SSRIs and diuretics was the most frequent PIP of ADs (17.6\%), followed by the prescription of TCAs $(12.9 \%)$, and concomitant prescription of SSRIs and non-steroidal antiinflammatory drugs (NSAIDs) or anti-vitamin K drugs, in $6.0 \%$ and $3.8 \%$ of the study population respectively.

\section{Factors associated with PIP of AD}

Bivariate analysis showed that PIP of ADs was associated with low self-perceived health, hospitalization in the prior six months, polypharmacy, number of chronic diseases, and cognitive impairment. Conversely, PIP of ADs was not associated with the level of education, tobacco smoking, alcohol consumption, nutritional impairment, impaired mobility, the use of other psychotropic drugs, level of dependency or sensory impairment (Table 2). Polypharmacy and comorbidity were the only factors that remained significantly associated with PIP of ADs in multivariate analysis. Polypharmacy was associated with PIP of ADs with adjusted OR $_{5-9}$ drugs 2.61 (95\% CI 1.116.16 and $\mathrm{OR}_{\geq 10 \text { drugs }} 2.69$ (95\% CI 1.06-6.87), independently of the number of chronic diseases and cognitive impairment (Table 4).

Subgroup analysis among people who reported the duration of their depressive and/or anxiety symptoms $(n=160)$ showed that the longer the duration of symptoms, the higher the risk of PIP of ADs, with an adjusted OR 2.82 (95\% CI 1.42-6.99) for people suffering from depressive and/or anxiety symptoms for $\geq 28$ years relative to those who reported symptoms for $\leq 7$ years.

\section{PIP of AD and mortality}

During follow-up, $29.5 \%$ of people with at least one PIP of ADs died, versus $18.4 \%$ of those a PIP of ADs $(\mathrm{p}=0.025)$. PIP of AD was associated with increased mortality (HR 2.30,95\% CI 1.28-4.12) after adjustment for age, gender, polypharmacy, number of chronic diseases, nutritional impairment, cognitive impairment, dependency, hospitalization in the prior six months, and GDS score (Table 5, survival curves available in Appendix 1).

\section{Discussion}

\section{Main findings}


Based on international and national guidelines, we found that $36.8 \%$ of people $\geq 70$ years received a priori suboptimal AD treatment in a French observational study. Drug-drug interactions between SSRIs and diuretics and prescription of TCAs were the most frequent PIPs. In multivariate analysis, the only factors associated with PIP of ADs were polypharmacy and comorbidity. Survival analysis (median follow-up of 2.8 years) suggests that PIP of ADs is associated with increased mortality among AD users.

\section{Drug-drug interactions with SSRIs}

The most frequently reported PIP of ADs was the association of SSRIs and diuretics (17.6\%). This association increases the risk of hyponatremia caused by SSRIs, especially when thiazide diuretics are involved (Mannesse et al., 2013). Hyponatremia is associated with cognitive impairment (Gunathilake et al., 2013) and increases the risk of osteoporosis and bone fractures (Usala et al., 2015). The biological mechanisms of this interaction may involve syndrome of inappropriate secretion of antidiuretic hormone (SIADH) or nephrogenic syndrome of inappropriate antidiuresis (NSIAD) by increasing sensitivity of the kidneys to ADH via aquaporine-2 expression (Mannesse et al., 2013).

Here, concomitant use of SSRIs with NSAIDs or antivitamin K drugs represented $6.0 \%$ and $3.8 \%$ of the PIP of ADs respectively. There is evidence that SSRIs increase the risk of upper gastrointestinal bleeding, particularly when they are associated with NSAIDs (de Abajo and García-Rodríguez, 2008). The role of serotonin in the ability of platelets to aggregate may explain this effect. Indeed, the use of SSRIs has been shown to increase the risk of major haemorrhage events in patients taking warfarin (Quinn et al., 2014). Antivitamin K drugs are biotransformed by the P450 system and SSRIs potentially inhibit various isoenzymes (Sansone and Sansone, 2009). Thus, it is recommended that people treated with warfarin and starting treatment with an SSRI have their International Normalized Ratio (INR) regularly monitored to detect interactions (Afssaps, 2006; Lam et al., 2015; Pilling et al., 2009).

\section{TCAs}

In our study, TCAs represented the second most frequent PIP of ADs, with a prevalence of $12.9 \%$ among $\mathrm{AD}$ users. This is similar to the results of a cross-sectional study among 1306 inpatients aged $\geq 75$ years in France (Prudent et al., 2008). Among the 263 inpatients treated by ADs, 29 (11\%) received TCAs. Amitriptyline has been identified as the most inappropriately prescribed $\mathrm{AD}$ among people $\geq 65$ years in community settings (Opondo et al., 2012) and nursing homes (Bourgeois et al., 2012). Reasons for the use of TCAs, and amitriptyline in particular, may involve the management of treatment-resistant depression, indications for 
conditions other than depression itself (such as neuropathic pain) and off-label use (e.g. for pain, insomnia, and migraine) (Wong et al., 2017). TCAs may have notable side effects resulting from their strong anticholinergic activity (i.e. dry mouth, blurred vision, urinary retention, and constipation) and cardiovascular adverse effects (i.e. orthostatic hypotension and arrhythmia) (Gareri et al., 2000; Mintzer and Burns, 2000). Thus, TCA are not recommended as a first-line treatment (Afssaps, 2006; O’Mahony et al., 2015). An Australian study (Caughey et al., 2010) showed that approximately one third of patients receiving TCAs had arrhythmia, ischemic heart disease or chronic heart failure. The prevalence of concomitant cardiovascular fragility and TCAs prescription in our study was very low (3\%) but this may be an under-estimation, as information concerning cardiovascular diseases was not extensively detailed in the SIPAF study.

\section{Factors associated with PIP of ADs}

The main factors associated with PIP of ADs were polypharmacy and comorbidity. This finding was expected because polypharmacy, related to comorbidity, is a well-known determinant of PIP in general (Projovic et al., 2016) and of PIP of psychotropic drugs in particular (Carey et al., 2008). Although expected, this result is worrisome because of the very large proportion of our sample of AD users exposed to polypharmacy $(86.1 \%$ received at least 5 medications, versus $67.4 \%$ in the entire population of the SIPAF study). This study highlights the need for review of drug therapy among elderly AD users, by considering the appropriateness of each drug, both individually and in the context of the other drugs being prescribed (Wise, 2013).

In a subgroup analysis, the duration of depression and/or anxiety symptoms was also associated with PIP of ADs. This association has not been reported elsewhere and suggests that prolonged AD treatment increases the risk of PIP, probably because the prescription is not reassessed. Furthermore, long-term prescription of AD treatment may be contraindicated because of the risks of osteoporosis and fractures (Diniz and Reynolds, 2014).

\section{Association between PIP of ADs and mortality}

This study suggests that PIP of ADs is significantly associated with mortality. Previous findings regarding the association between inappropriate prescribing, not restricted to ADs, and mortality are contradictory. Both positive (Sköldunger et al., 2015) and negative associations (Onder et al., 2005; Page and Ruscin, 2006) have been reported. Methodological issues may explain these discrepancies, such as the lack of adjustment for important confounders (e.g. number of chronic diseases, polypharmacy), short follow-up or small and selected samples. Concerning inappropriate prescribing of ADs or other psychotropic drugs, previous observational studies suggested an association with mortality, although they encountered difficulty distinguishing the effect of 
AD drugs from those of depression itself. The results of our study were adjusted for the intensity of depressive symptoms according to the GDS 15 , but we cannot exclude residual confounding.

\section{Strength and limitations of the study}

The main strength of the SIPAF study was the collection of diverse health data among a sample of elderly recruited from throughout mainland France, including a large proportion of oldest-old. Concerning medication data, the examination of participants' prescriptions at home minimized recall bias.

We performed a comprehensive assessment of PIP of ADs, using validated and updated explicit criteria (2015 Beers, Laroche and STOPP version 2), as well as recommendations. Explicit tools have many advantages, as they are highly reproducible and applicable to large scale studies of patients at a limited cost, and have demonstrated their utility in assessing the quality of drug therapy at the population level (Morin et al., 2015). However, they artificially simplify complex situations by excluding the individuals' health history and preferences (Spinewine et al., 2007).

The SIPAF study was not specifically designed to answer the questions of the present study. Thus, we lack useful information regarding $\mathrm{AD}$ prescriptions, notably the indication, dosage, and duration of treatment. Consequently, we could not analyze underuse or overuse, nor misuse of ADs taking into account the symptoms that led to the prescription of $\mathrm{AD}$, which may be depressive and/or anxiety disorders but also neuropathic pain (TCAs). Furthermore, the association between the duration of depressive and/or anxiety symptoms and PIP of ADs should be interpreted with caution because data may suffer from recall bias.

Concerning the association between PIP of ADs and mortality, we cannot exclude residual confounding by morbidity because we used a standard list of 14 chronic diseases that does not take into account their severity. Finally, mortality is not the ultimate arbiter of risk and benefit for medications but we were unable to measure the impact of PIP of ADs on adverse drug events or quality of life, nor could we assess the potential clinical benefits of $\mathrm{AD}$ use.

\section{Conclusion}

PIP of ADs was observed among more than one third of our study population aged $\geq 70$ years and mainly involved interactions between SSRIs and diuretics and the prescription of TCAs. PIP of ADs was associated with polypharmacy and comorbidity and increased the risk of mortality among AD users. These findings highlight the 
need for greater caution in the use of ADs in the elderly. Areas for improvement may include specific training of General Practitioners, facilitating access to geriatric or psychiatric consultations, and reinforcement of the role of the community pharmacist in medication review. Both observational and interventional studies are needed to assess the long-term consequences of PIP of ADs and evaluate the effects of de-prescription of ADs in old people.

Conflicts of interest: None to declare. Anne Hiance-Delahaye carried out the statistical analysis and wrote the paper. Marie Herr supervised the statistical analysis and helped to write the paper. Joël Ankri, Jean-Marie Robine and Jean-Jacques Arvieu designed the SIPAF study, supervised data collection, and critically reviewed the paper. Florence Muller, Laurent Lechowski and, Laurent Teillet critically reviewed the paper.

Acknowledgments: Thanks to Alex Edelman \& Associates for English editing. 


\section{References}

Afssaps, 2006. Bon usage des medicaments antidepresseurs dans le traitement des troubles depressifs et des troubles anxieux de l'adulte. Afssaps.

American Geriatrics Society 2015 Beers Criteria Update Expert Panel, 2015. American Geriatrics Society 2015 Updated Beers Criteria for Potentially Inappropriate Medication Use in Older Adults. J. Am. Geriatr. Soc. 63, 2227-2246. doi:10.1111/jgs.13702

Bourgeois, J., Elseviers, M.M., Van Bortel, L., Petrovic, M., Vander Stichele, R.H., 2012. The use of antidepressants in Belgian nursing homes: focus on indications and dosages in the PHEBE study. Drugs Aging 29, 759-769. doi:10.1007/s40266-012-0003-6

Carey, I.M., De Wilde, S., Harris, T., Victor, C., Richards, N., Hilton, S.R., Cook, D.G., 2008. What factors predict potentially inappropriate primary care prescribing in older people? Analysis of UK primary care patient record database. Drugs Aging 25, 693-706.

Caughey, G.E., Roughead, E.E., Shakib, S., McDermott, R.A., Vitry, A.I., Gilbert, A.L., 2010. Comorbidity of chronic disease and potential treatment conflicts in older people dispensed antidepressants. Age Ageing 39, 488-494. doi:10.1093/ageing/afq055

de Abajo, F.J., García-Rodríguez, L.A., 2008. Risk of upper gastrointestinal tract bleeding associated with selective serotonin reuptake inhibitors and venlafaxine therapy: interaction with nonsteroidal anti-inflammatory drugs and effect of acid-suppressing agents. Arch. Gen. Psychiatry 65, 795-803. doi:10.1001/archpsyc.65.7.795

Diniz, B.S., Reynolds, C.F., 2014. Major Depressive Disorder in Older Adults: Benefits and Hazards of Prolonged Treatment. Drugs Aging. doi:10.1007/s40266-014-0196-y

Diniz, B.S., Reynolds, C.F., Butters, M.A., Dew, M.A., Firmo, J.O.A., Lima-Costa, M.F., CastroCosta, E., 2014. The effect of gender, age, and symptom severity in late-life depression on the risk of all-cause mortality: the Bambuí Cohort Study of Aging. Depress. Anxiety 31, 787-795. doi: $10.1002 /$ da. 22226 
Folstein, M.F., Folstein, S.E., McHugh, P.R., 1975. "Mini-mental state”. A practical method for grading the cognitive state of patients for the clinician. J. Psychiatr. Res. 12, 189-198.

Gareri, P., Falconi, U., De Fazio, P., De Sarro, G., 2000. Conventional and new antidepressant drugs in the elderly. Prog. Neurobiol. 61, 353-396.

Girardi, P., Pompili, M., Innamorati, M., Mancini, M., Serafini, G., Mazzarini, L., Del Casale, A., Tatarelli, R., Baldessarini, R.J., 2009. Duloxetine in acute major depression: review of comparisons to placebo and standard antidepressants using dissimilar methods. Hum. Psychopharmacol. 24, 177-190. doi:10.1002/hup.1005

Gunathilake, R., Oldmeadow, C., McEvoy, M., Kelly, B., Inder, K., Schofield, P., Attia, J., 2013. Mild hyponatremia is associated with impaired cognition and falls in community-dwelling older persons. J. Am. Geriatr. Soc. 61, 1838-1839. doi:10.1111/jgs.12468

Hanlon, J.T., Wang, X., Castle, N.G., Stone, R.A., Handler, S.M., Semla, T.P., Pugh, M.J., Berlowitz, D.R., Dysken, M.W., 2011. Potential Underuse, Overuse and Inappropriate Use of Antidepressants in Older Veteran Nursing Home Patients. J. Am. Geriatr. Soc. 59, 1412-1420. doi:10.1111/j.1532-5415.2011.03522.x

Herr, M., Arvieu, J.-J., Aegerter, P., Robine, J.-M., Ankri, J., 2014. Unmet health care needs of older people: prevalence and predictors in a French cross-sectional survey. Eur. J. Public Health 24, 808-813. doi:10.1093/eurpub/ckt179

Hollingworth, S.A., Lie, D.C., Siskind, D.J., Byrne, G.J., Hall, W.D., Whiteford, H.A., 2011. Psychiatric drug prescribing in elderly Australians: time for action. Aust. N. Z. J. Psychiatry 45, 705-708. doi:10.3109/00048674.2011.594947

Katz, S., Ford, A.B., Moskowitz, R.W., Jackson, B.A., Jaffe, M.W., 1963. Studies of Illness in the Aged: The Index of ADL: A Standardized Measure of Biological and Psychosocial Function. JAMA 185, 914-919. doi:10.1001/jama.1963.03060120024016

Kennedy, G.J., Marcus, P., 2005. Use of antidepressants in older patients with co-morbid medical conditions: guidance from studies of depression in somatic illness. Drugs Aging 22, 273-287. 
Knapp, Martin, McDaid, David, Mossialos, Elias, Thornicroft, Graham, 2006. WHO/Europe | Publications - Mental health policy and practice across Europe. The future direction of mental health care.

Kok, R.M., Reynolds, C.F., 2017. Management of Depression in Older Adults: A Review. JAMA 317, 2114-2122. doi:10.1001/jama.2017.5706

Lam, R.W., Parikh, S.V., Michalak, E.E., Dewa, C.S., Kennedy, S.H., 2015. Canadian Network for Mood and Anxiety Treatments (CANMAT) consensus recommendations for functional outcomes in major depressive disorder. Ann. Clin. Psychiatry Off. J. Am. Acad. Clin. Psychiatr. 27, 142-149.

Laroche, M.-L., Charmes, J.-P., Merle, L., 2007. Potentially inappropriate medications in the elderly: a French consensus panel list. Eur. J. Clin. Pharmacol. 63, 725-731. doi:10.1007/s00228-007$0324-2$

Lawton, M.P., Brody, E.M., 1969. Assessment of Older People: Self-Maintaining and Instrumental Activities of Daily Living. The Gerontologist 9, 179-186. doi:10.1093/geront/9.3_Part_1.179

Luppa, M., Sikorski, C., Luck, T., Ehreke, L., Konnopka, A., Wiese, B., Weyerer, S., König, H.-H., Riedel-Heller, S.G., 2012. Age- and gender-specific prevalence of depression in latest-life-systematic review and meta-analysis. J. Affect. Disord. 136, 212-221. doi:10.1016/j.jad.2010.11.033

Mannesse, C.K., Jansen, P.A.F., Van Marum, R.J., Sival, R.C., Kok, R.M., Haffmans, P.M.J., Egberts, T.C.G., 2013. Characteristics, prevalence, risk factors, and underlying mechanism of hyponatremia in elderly patients treated with antidepressants: a cross-sectional study. Maturitas 76, 357-363. doi:10.1016/j.maturitas.2013.08.010

Mintzer, J., Burns, A., 2000. Anticholinergic side-effects of drugs in elderly people. J. R. Soc. Med. 93, 457-462. doi:10.1177/014107680009300903

Mojtabai, R., Olfson, M., 2011. Proportion of antidepressants prescribed without a psychiatric diagnosis is growing. Health Aff. Proj. Hope 30, 1434-1442. doi:10.1377/hlthaff.2010.1024 
Moore, M., Yuen, H.M., Dunn, N., Mullee, M.A., Maskell, J., Kendrick, T., 2009. Explaining the rise in antidepressant prescribing: a descriptive study using the general practice research database. BMJ 339, b3999.

Morin, L., Fastbom, J., Laroche, M.-L., Johnell, K., 2015. Potentially inappropriate drug use in older people: a nationwide comparison of different explicit criteria for population-based estimates. Br. J. Clin. Pharmacol. 80, 315-324. doi:10.1111/bcp.12615

Mort, J.R., Aparasu, R.R., 2000. Prescribing potentially inappropriate psychotropic medications to the ambulatory elderly. Arch. Intern. Med. 160, 2825-2831.

Noordam, R., Aarts, N., Verhamme, K.M., Sturkenboom, M.C.M., Stricker, B.H., Visser, L.E., 2015. Prescription and indication trends of antidepressant drugs in the Netherlands between 1996 and 2012: a dynamic population-based study. Eur. J. Clin. Pharmacol. 71, 369-375. doi:10.1007/s00228-014-1803-x

Olfson, M., Marcus, S.C., 2009. National patterns in antidepressant medication treatment. Arch. Gen. Psychiatry 66, 848-856. doi:10.1001/archgenpsychiatry.2009.81

O’Mahony, D., O’Sullivan, D., Byrne, S., O’Connor, M.N., Ryan, C., Gallagher, P., 2015. STOPP/START criteria for potentially inappropriate prescribing in older people: version 2. Age Ageing 44, 213-218. doi:10.1093/ageing/afu145

Onder, G., Landi, F., Liperoti, R., Fialova, D., Gambassi, G., Bernabei, R., 2005. Impact of inappropriate drug use among hospitalized older adults. Eur. J. Clin. Pharmacol. 61, 453-459. doi:10.1007/s00228-005-0928-3

Opondo, D., Eslami, S., Visscher, S., de Rooij, S.E., Verheij, R., Korevaar, J.C., Abu-Hanna, A., 2012. Inappropriateness of medication prescriptions to elderly patients in the primary care setting: a systematic review. PloS One 7, e43617. doi:10.1371/journal.pone.0043617

Page, R.L., Ruscin, J.M., 2006. The risk of adverse drug events and hospital-related morbidity and mortality among older adults with potentially inappropriate medication use. Am. J. Geriatr. Pharmacother. 4, 297-305. doi:10.1016/j.amjopharm.2006.12.008 
Pilling, S., Anderson, I., Goldberg, D., Meader, N., Taylor, C., Two Guideline Development Groups, 2009. Depression in adults, including those with a chronic physical health problem: summary of NICE guidance. BMJ 339, b4108.

Projovic, I., Vukadinovic, D., Milovanovic, O., Jurisevic, M., Pavlovic, R., Jacovic, S., Jankovic, S., Stefanovic, S., 2016. Risk factors for potentially inappropriate prescribing to older patients in primary care. Eur. J. Clin. Pharmacol. 72, 93-107. doi:10.1007/s00228-015-1957-1

Prudent, M., Dramé, M., Jolly, D., Trenque, T., Parjoie, R., Mahmoudi, R., Lang, P.-O., Somme, D., Boyer, F., Lanièce, I., Gauvain, J.-B., Blanchard, F., Novella, J.-L., 2008. Potentially inappropriate use of psychotropic medications in hospitalized elderly patients in France: crosssectional analysis of the prospective, multicentre SAFEs cohort. Drugs Aging 25, 933-946.

Quinn, G.R., Singer, D.E., Chang, Y., Go, A.S., Borowsky, L.H., Udaltsova, N., Fang, M.C., 2014. Effect of selective serotonin reuptake inhibitors on bleeding risk in patients with atrial fibrillation taking warfarin. Am. J. Cardiol. 114, 583-586. doi:10.1016/j.amjcard.2014.05.037

Raymond, C.B., Morgan, S.G., Caetano, P.A., 2007. Antidepressant utilization in British Columbia from 1996 to 2004: increasing prevalence but not incidence. Psychiatr. Serv. Wash. DC 58, 79-84. doi:10.1176/appi.ps.58.1.79-a

Robine, J.-M., Jagger, C., Euro-REVES Group, 2003. Creating a coherent set of indicators to monitor health across Europe: the Euro-REVES 2 project. Eur. J. Public Health 13, 6-14.

Ruths, S., Sørensen, P.H., Kirkevold, Ø., Husebø, B.S., Krüger, K., Halvorsen, K.H., Selbaek, G., 2013. Trends in psychotropic drug prescribing in Norwegian nursing homes from 1997 to 2009: a comparison of six cohorts. Int. J. Geriatr. Psychiatry 28, 868-876. doi:10.1002/gps.3902

Sansone, R.A., Sansone, L.A., 2009. Warfarin and Antidepressants: Happiness without Hemorrhaging. Psychiatry Edgmont Pa Townsh. 6, 24-29.

Sköldunger, A., Fastbom, J., Wimo, A., Fratiglioni, L., Johnell, K., 2015. Impact of Inappropriate Drug Use on Hospitalizations, Mortality, and Costs in Older Persons and Persons with 
Dementia: Findings from the SNAC Study. Drugs Aging 32, 671-678. doi:10.1007/s40266015-0287-4

Spinewine, A., Schmader, K.E., Barber, N., Hughes, C., Lapane, K.L., Swine, C., Hanlon, J.T., 2007. Appropriate prescribing in elderly people: how well can it be measured and optimised? The Lancet 370, 173-184. doi:10.1016/S0140-6736(07)61091-5

Usala, R.L., Fernandez, S.J., Mete, M., Cowen, L., Shara, N.M., Barsony, J., Verbalis, J.G., 2015. Hyponatremia Is Associated With Increased Osteoporosis and Bone Fractures in a Large US Health System Population. J. Clin. Endocrinol. Metab. 100, 3021-3031. doi:10.1210/jc.20151261

Volkert, J., Schulz, H., Härter, M., Wlodarczyk, O., Andreas, S., 2013. The prevalence of mental disorders in older people in Western countries - a meta-analysis. Ageing Res. Rev. 12, 339353. doi:10.1016/j.arr.2012.09.004

Wang, P.S., Schneeweiss, S., Brookhart, M.A., Glynn, R.J., Mogun, H., Patrick, A.R., Avorn, J., 2005. Suboptimal antidepressant use in the elderly. J. Clin. Psychopharmacol. 25, 118-126.

Wise, J., 2013. Polypharmacy: a necessary evil. BMJ 347, f7033. doi:10.1136/bmj.f7033

Wong, J., Motulsky, A., Abrahamowicz, M., Eguale, T., Buckeridge, D.L., Tamblyn, R., 2017. Offlabel indications for antidepressants in primary care: descriptive study of prescriptions from an indication based electronic prescribing system. BMJ 356, j603.

Yesavage, J.A., Brink, T.L., Rose, T.L., Lum, O., Huang, V., Adey, M., Leirer, V.O., 1982.

Development and validation of a geriatric depression screening scale: a preliminary report. J. Psychiatr. Res. 17, 37-49. 
Table 1. Prevalence of PIP of ADs according to national and international criteria (Beers, Laroche, STOPP/START and prescription guidelines)

\begin{tabular}{|c|c|c|c|c|c|}
\hline Risk medications used & Medication name & $\begin{array}{l}\text { WHO ATC } \\
\text { classification }\end{array}$ & Potential(s) risk(s) & Reference(s) & n $(\%)^{(* * * *)}$ \\
\hline TCA alone & $\begin{array}{l}\text { Amitriptyline } \\
\text { Clomipramine } \\
\text { Imipramine } \\
\text { Trimipramine } \\
\text { Doxepine } \\
\text { Amoxapine } \\
\text { Maprotiline } \\
\text { Dosulepine }\end{array}$ & $\begin{array}{l}\text { N06AA09 } \\
\text { N06AA04 } \\
\text { N06AA02 } \\
\text { N06AA06 } \\
\text { N06AA12 } \\
\text { N06AA17 } \\
\text { N06AA21 } \\
\text { N06AA16 } \\
\end{array}$ & $\begin{array}{l}\text { Highly anticholinergic, sedative } \\
\text { and causes orthostatic } \\
\text { hypotension }\end{array}$ & $\begin{array}{l}\text { Laroche et al. (2009) } \\
\text { Beers et al. (2015) }\end{array}$ & $41(12.9)$ \\
\hline TCA associated with calcium inhibitors or opioids & & C08 and N02A & May exacerbate constipation & O’Mahony et al. (2015) & $12(3.7)$ \\
\hline TCA associated with cardio-vascular fragility ${ }^{\left({ }^{* *}\right)}$ & & & $\begin{array}{l}\text { Increases the risk of cardiac } \\
\text { events (cardiac conduction } \\
\text { slowing, arrhythmia, orthostatic } \\
\text { hypotension) }\end{array}$ & $\begin{array}{l}\text { Beers et al. (2015) } \\
\text { O'Mahony et al. (2015) }\end{array}$ & $9(2.8)$ \\
\hline TCA associated with cognitive impairment ${ }^{(*)}$ & & & $\begin{array}{l}\text { Risk of worsening cognitive } \\
\text { impairment }\end{array}$ & O’Mahony et al. (2015) & $6(1.9)$ \\
\hline TCA associated with anticholinergic drugs & $\begin{array}{l}\text { Phenothiazine } \\
\text { neuroleptic } \\
\text { Doxylamine } \\
\text { Aceprometazine } \\
\text { Alimemazine } \\
\text { Promethazine } \\
\text { Mequitazine } \\
\text { Carbinoxamine } \\
\text { Hydroxyzine } \\
\text { Brompheniramine } \\
\text { Chlorphenamine } \\
\text { Cyproheptadine } \\
\text { Buclizine } \\
\text { Oxybutynine } \\
\text { Tolterodine } \\
\text { Solifenacine }\end{array}$ & $\begin{array}{l}\text { N05AA and } \\
\text { N05AC } \\
\text { R06AA09 } \\
\text { N05CV01 } \\
\text { R06AD01 } \\
\text { N06AD02 } \\
\text { R06AD07 } \\
\text { R06AA09 } \\
\text { N05BB01 } \\
\text { R06AD01 } \\
\text { R06AB04 } \\
\text { R06AX02 } \\
\text { R06AE51 } \\
\text { G04BD04 } \\
\text { G04BD07 } \\
\text { G04BD08 }\end{array}$ & Increases anticholinergic effects & $\begin{array}{l}\text { Lang et al. (2015) } \\
\text { Laroche et al. (2009) }\end{array}$ & 0 \\
\hline SSRI associated with diuretics & & $\begin{array}{l}\text { N06AB and } \\
\text { C03 }\end{array}$ & Increases risk of hyponatremia & $\begin{array}{l}\text { Beers et al. (2015) } \\
\text { ANSM (2006) }\end{array}$ & $56(17.6)$ \\
\hline
\end{tabular}


Increases risk of gastrointestinal bleeding

N02BA

Concomitant use of two ADs

No improved efficacy but

NICE (2009)

CANMAT (2009)

Laroche et al. (2009)

O'Mahony et al. (2015)

Abbreviations; ADs = antidepressants; ANSM = Agence Nationale de Securité des Medicaments; CANMAT = Canadian Network for Mood and Anxiety Treatments; NICE = National Institute for Health and Clinical

Excellence; NSAIDs = non-steroidal anti-inflammatory drugs; PIP of ADs = Potentially Inappropriate Prescription of Antidepressants; SNRIs = serotonin-norepinephrine reuptake inhibitors; SSRIs = selective serotonin reuptake inhibitors; TCAs = tricyclic antidepressants.

(*) Cognitive impairment defined as a score lower than 26 to the Mini-Mental State Examination and/or prescription of an anti-Alzheimer drug.

(**) Cardiovascular fragility defined as prescription of at least one of the following drugs: antiarrhythmic or digitalic or coronary vasodilator drugs.

(***) The total number of PIP is greater than 117 because some participants had multiple PIPs. 


\begin{tabular}{|c|c|c|c|c|}
\hline Variables & $\begin{array}{l}\text { Total, } \mathrm{N}=\mathbf{3 1 8} \\
\text { n (\%) }\end{array}$ & $\begin{array}{l}\text { Group with } \\
\text { PIP of ADs, } \\
\mathrm{N}=117 \\
\mathrm{n}(\%)\end{array}$ & $\begin{array}{l}\text { Group without } \\
\text { PIP of ADs, } \\
\text { N=201 } \\
\text { n }(\%)\end{array}$ & $\mathbf{p}$ \\
\hline \multicolumn{5}{|c|}{ Socio-demographic characteristics, lifestyle, and general health } \\
\hline \multicolumn{5}{|c|}{ Age group } \\
\hline - $\quad 70-89$ years & $92(28.9)$ & $32(27.4)$ & $60(29.9)$ & 0.444 \\
\hline - $\quad 80-89$ years & $157(49.4)$ & $63(53.8)$ & $94(46.8)$ & \\
\hline$-\quad \geq 90$ years & $69(21.7)$ & $22(18.8)$ & $47(23.4)$ & \\
\hline \multicolumn{5}{|l|}{ Gender } \\
\hline - Male & $92(28.9)$ & $30(25.6)$ & $62(30.8)$ & 0.324 \\
\hline - Female & $226(71.1)$ & $87(74.4)$ & $139(69.2)$ & \\
\hline \multicolumn{5}{|l|}{ Level of education } \\
\hline - $\quad$ Low (less than 7 years) & $101(32.1)$ & $33(28.5)$ & $68(34.2)$ & 0.576 \\
\hline - $\quad$ Intermediate (between 7 and 10 years) & $157(49.8)$ & $61(52.6)$ & $96(48.2)$ & \\
\hline - $\quad$ High (more than 10 years) & $57(18.1)$ & $22(19.0)$ & $35(17.6)$ & \\
\hline \multicolumn{5}{|l|}{ Socio professional category (couple) } \\
\hline - Low & $51(16.0)$ & $18(15.4)$ & $33(16.4)$ & 0.966 \\
\hline - Intermediate & $158(49.7)$ & $59(50.4)$ & $99(49.3)$ & \\
\hline - High & $109(34.3)$ & $40(34.2)$ & $69(34.3)$ & \\
\hline Married or living in couple & $110(34.7)$ & $42(36.2)$ & $68(33.8)$ & 0.875 \\
\hline Tobacco smoking & $120(37.7)$ & $40(34.2)$ & $80(39.8)$ & 0.319 \\
\hline Alcohol consumption ( 3 or more glasses per day) & $13(7.5)$ & $4(6.7)$ & $9(8.0)$ & 0.758 \\
\hline \multicolumn{5}{|l|}{ Self-rating of health relative to -people of the same age } \\
\hline - Better & $86(28.7)$ & $24(21.8)$ & $62(32.6)$ & $0.134 *$ \\
\hline - Similar & $173(57.7)$ & $70(63.6)$ & $103(54.2)$ & \\
\hline - Worse & $41(13.7)$ & $16(14.5)$ & $25(13.2)$ & \\
\hline Hospitalization in the prior 6 months & $65(20.7)$ & $29(25.4)$ & $36(18)$ & $0.118^{*}$ \\
\hline \multicolumn{5}{|l|}{ Geriatric assessment } \\
\hline Nutritionnal impairment & $55(17.5)$ & $18(15.5)$ & $37(18.6)$ & 0.488 \\
\hline \multicolumn{5}{|l|}{ Cognitive impairment (score on MMSE) } \\
\hline$->26$ & $242(80.4)$ & $88(77.9)$ & $154(82.0)$ & $0.183^{*}$ \\
\hline$-\quad 20-26$ & $33(11.0)$ & $17(15.0)$ & $16(8.5)$ & \\
\hline$-\quad<20$ & $26(8.6)$ & $8(7.1)$ & $18(9.6)$ & \\
\hline \multicolumn{5}{|l|}{ Number of chronic diseases } \\
\hline$-\quad 0-2$ & $40(12.7)$ & $9(7.6)$ & $31(15.7)$ & $0.126^{*}$ \\
\hline$-\quad 3-4$ & $130(41.4)$ & $50(43.1)$ & $80(40.4)$ & \\
\hline$-\quad \geq 5$ & $144(45.9)$ & $57(49.1)$ & 87 (43.9) & \\
\hline Impaired mobility ${ }^{\text {(a) }}$ & $130(79.8)$ & $51(81.0)$ & $79(79)$ & 0.763 \\
\hline \multicolumn{5}{|l|}{ Polypharmacy } \\
\hline - $\quad 1-4$ drugs & $44(13.8)$ & $8(6.8)$ & $36(17.9)$ & $0.019^{*}$ \\
\hline - $\quad 5-9$ drugs & $181(56.9)$ & $70(59.8)$ & $111(55.2)$ & \\
\hline$-\quad \geq 10$ drugs & $93(29.2)$ & $39(33.3)$ & $54(26.8)$ & \\
\hline \multicolumn{5}{|l|}{ Use of other psychotropic drugs } \\
\hline - $\quad$ Anxiolytic and/or hypnotic drugs & $159(50.0)$ & $59(50.4)$ & $100(49.8)$ & 0.907 \\
\hline - $\quad$ Antipsychotic drugs & $14(4.4)$ & $7(6.0)$ & $7(3.5)$ & 0.295 \\
\hline \multicolumn{5}{|l|}{ Level of dependency } \\
\hline - Independent & $136(42.8)$ & $48(41.0)$ & $88(43.8)$ & 0.830 \\
\hline - $\quad$ Need of help for $\geq 1$ ADL & $85(26.7)$ & $31(26.5)$ & $54(26.9)$ & \\
\hline - $\quad$ Need of help for $\geq 1$ IADL & $97(30.6)$ & $38(32.5)$ & $59(29.4)$ & \\
\hline \multicolumn{5}{|l|}{ Urinary incontinence } \\
\hline - Never & $165(52.2)$ & $60(52.2)$ & $105(52.2)$ & 0.294 \\
\hline - Occasional & $84(26.6)$ & $26(22.6)$ & $58(28.9)$ & \\
\hline - Regular & $67(21.2)$ & $29(25.2)$ & $38(18.9)$ & \\
\hline \multicolumn{5}{|l|}{ Depressive syndrome (score on 15-item GDS) } \\
\hline$-\quad<5$ & $199(63.0)$ & $72(61.5)$ & $127(63.8)$ & 0.826 \\
\hline$-\quad 5-10$ & $86(27.2)$ & $32(27.4)$ & $54(27.1)$ & \\
\hline$->10$ & $31(9.8)$ & $13(11.1)$ & $18(9.0)$ & \\
\hline \multicolumn{5}{|l|}{ Number of years with anxiety and/or depression } \\
\hline$-\quad 0-7$ & $63(37.7)$ & $10(16.7)$ & $45(42.1)$ & $0.048 *$ \\
\hline$-\quad 8-27$ & $61(36.5)$ & $12(20.0)$ & $41(38.3)$ & \\
\hline$-\quad \geq 28$ & $43(25.8)$ & $38(63.3)$ & $21(19.6)$ & \\
\hline Social isolation ${ }^{(b)}$ & $123(38.7)$ & $49(33.3)$ & $74(36.8)$ & 0.371 \\
\hline Visual impairment & $52(16.8)$ & $20(17.4)$ & $32(16.4)$ & 0.823 \\
\hline Hearing impairment & $128(40.3)$ & $42(35.9)$ & $86(42.8)$ & 0.227 \\
\hline
\end{tabular}

Abbreviations: ADL = Activities of daily living; GDS = Geriatric Depression Scale; IADL = Instrumental Activities of Daily Living; MMSE = Mini

Mental State Evaluation; PIP of ADs = Potentially Inappropriate Prescription of Antidepressants.

(a) Impaired mobility was defined by difficulty walking more than 500 meters and/or difficulty walking up and down one floor of stairs.

(b) Social isolation was defined by lack of support with practical features (when bedridden or when needing to be accompanied to a medical appointment or when needing help to prepare meals) and/or emotional features (when needing to talk or when needing advice or affection) $* \mathrm{p}<0.20$ 
Table 3. Use of ADs in the study population $(n=318)$

\begin{tabular}{|c|c|}
\hline Classes of ADs & n (\%) \\
\hline $\begin{aligned} \text { TCAs } & \\
\text { - } & \text { Amitriptyline } \\
\text { - } & \text { Clomipramine } \\
\text { - } & \text { Dosulépine } \\
\text { - } & \text { Maprotiline } \\
\text { - } & \text { Trimipramine } \\
\text { - } & \text { Amoxapine }\end{aligned}$ & $\begin{array}{l}41(12.9) \\
21(6.6) \\
12(3.8) \\
4(1.3) \\
2(0.6) \\
1(0.3) \\
1(0.3)\end{array}$ \\
\hline $\begin{array}{cl}\text { SSRIs } & \\
\text { - } & \text { Paroxetine } \\
\text { - } & \text { Escitalopram } \\
\text { - } & \text { Citalopram } \\
\text { - } & \text { Fluoxetine } \\
\text { - } & \text { Sertraline } \\
\text { - } & \text { Fluvoxamine }\end{array}$ & $\begin{array}{l}159(50) \\
63(19.8) \\
30(9.4) \\
30(9.4) \\
18(5.7) \\
17(5.3) \\
1(0.3)\end{array}$ \\
\hline $\begin{array}{cl}\text { SNRIs } & \\
- & \text { Venlafaxine } \\
- & \text { Duloxetine } \\
\text { - } & \text { Milnacipran }\end{array}$ & $\begin{array}{l}46(14.4) \\
34(10.7) \\
10(3.1) \\
2(0.6)\end{array}$ \\
\hline $\begin{array}{cc}\text { MAOIs } & \\
- & \text { Moclobemide }\end{array}$ & $2(0.6)$ \\
\hline $\begin{array}{cl}\text { Others } & \\
- & \text { Mianserin } \\
- & \text { Tianeptine } \\
- & \text { Mirtazapine }\end{array}$ & $\begin{array}{l}81(25.5) \\
39(12.3) \\
29(9.1) \\
13(4.1)\end{array}$ \\
\hline
\end{tabular}

Abbreviations: ADs: antidepressants; MAOIs = monoamine oxidase inhibitors; SNRIs = serotonin-norepinephrine reuptake inhibitors; SSRIs $=$ selective serotonin reuptake inhibitors; TCAs $=$ tricyclic antidepressants. 
Table 4. Factors associated with PIP of ADs: results of the unadjusted and adjusted analysis

\begin{tabular}{|c|c|c|c|c|c|}
\hline \multicolumn{2}{|c|}{ Variables } & Crude OR (95\% CI) & $\mathbf{p}$ & Adjusted OR (95\% CI) & $\mathbf{p}$ \\
\hline \multicolumn{6}{|c|}{ Age group } \\
\hline- & $70-79$ years & 1.00 & & 1.00 & \\
\hline- & $80-89$ years & $1.26(0.74-2.14)$ & 0.402 & $1.10(0.62-1.94)$ & 0.761 \\
\hline- & 90 years and older & $0.88(0.45-1.70)$ & 0.700 & $0.82(0.39-1.73)$ & 0.605 \\
\hline \multicolumn{6}{|c|}{ Gender } \\
\hline- & Female & 1.00 & & 1.00 & \\
\hline- & Male & $0.77(0.46-1.29)$ & 0.324 & $0.69(0.40-1.20)$ & 0.194 \\
\hline \multicolumn{6}{|c|}{ Cognitive impairment (score on } \\
\hline MMS & & 1.00 & & 1.00 & \\
\hline- & $>26$ & $1.86(0.89-3.86)$ & 0.096 & $2.17(0.99-4.75)$ & 0.053 \\
\hline- & $20-26$ & $0.78(0.35-1.86)$ & 0.573 & $1.11(0.43-2.89)$ & 0.830 \\
\hline- & $<20$ & & & & \\
\hline \multicolumn{6}{|c|}{ Number of chronic diseases } \\
\hline- & $0-2$ & 1.00 & & 1.00 & \\
\hline- & $3-4$ & $2.15(0.95-4.90)$ & 0.067 & $2.59(1.04-6.44)$ & $0.041^{*}$ \\
\hline- & $\geq 5$ & $2.26(1.00-5.09)$ & 0.050 & $2.33(0.94-5.79)$ & 0.069 \\
\hline \multicolumn{6}{|c|}{ Polypharmacy } \\
\hline- & $1-4$ drugs & 1.00 & & 1.00 & \\
\hline- & 5-9 drugs & $2.84(1.25-6.46)$ & $0.013^{*}$ & 2. $61(1.11-6.16)$ & $0.029 *$ \\
\hline- & $\geq 10$ drugs & $3.25(1.36-7.76)$ & $0.008^{*}$ & $2.69(1.06-6.87)$ & $0.038^{*}$ \\
\hline
\end{tabular}

Abbreviations: OR = Odds Ratio; MMSE = Mini Mental State Evaluation; PIP of ADs = Potentially Inappropriate Prescription of Antidepressants

$* \mathrm{p}<0.05$ 
Table 5. Influence of PIP of ADs on survival (median follow-up of 2.8 years): results of the unadjusted and adjusted survival analysis

\begin{tabular}{|c|c|c|c|c|c|}
\hline \multicolumn{2}{|c|}{ Variables } & Crude HR (95\% CI) & $\mathbf{p}$ & Adjusted HR (95\% CI) & $\mathbf{p}$ \\
\hline \multicolumn{6}{|c|}{ Age group } \\
\hline- & $70-79$ years & 1.00 & & 1.00 & \\
\hline - & $80-89$ years & $3.61(1.61-8.10)$ & $0.002 *$ & $3.87(1.47-10.23)$ & $0.006^{*}$ \\
\hline- & 90 years and older & $6.09(2.62-14.16)$ & $<0.001^{*}$ & $3.37(1.18-9.69)$ & $0.024 *$ \\
\hline \multicolumn{6}{|c|}{ Gender } \\
\hline- & Female & 1.00 & & 1.00 & \\
\hline- & Male & $3.22(2.00-5.18)$ & $<0.001^{*}$ & $4.81(2.72-8.49)$ & $<0.001 *$ \\
\hline \multicolumn{6}{|c|}{ Hospitalization in the prior 6 months } \\
\hline- & No & 1.00 & & 1.00 & \\
\hline- & Yes & $2.01(1.21-3.35)$ & $0.007^{*}$ & $1.95(1.05-3.63)$ & $0.035^{*}$ \\
\hline \multicolumn{6}{|c|}{ Cognitive impairment (score on MMSE) } \\
\hline- & $>26$ & 1.00 & & 1.00 & \\
\hline- & $20-26$ & $2.63(1.33-5.17)$ & $0.005^{*}$ & $2.29(1.07-4.89)$ & 0.032 \\
\hline- & $<20$ & $3.37(1.72-6.63)$ & $<0.001 *$ & $3.40(1.43-8.06)$ & $0.006^{*}$ \\
\hline \multicolumn{6}{|c|}{ Level of dependency } \\
\hline- & Independent & 1.00 & & 1.00 & \\
\hline- & Need of help for $\geq 1$ ADL & $2.23(1.10-4.53)$ & $0.027^{*}$ & $3.20(1.37-7.46)$ & $0.007^{*}$ \\
\hline- & Need of help for $\geq 1$ IADL & $4.73(2.56-8.75)$ & $<0.001^{*}$ & $3.42(1.55-7.54)$ & $0.002 *$ \\
\hline \multicolumn{6}{|c|}{ Number of chronic diseases } \\
\hline- & $0-2$ & 1.00 & & 1.00 & \\
\hline- & $3-4$ & $1.24(0.62-2.47)$ & 0.543 & $1.16(0.52-2.59)$ & 0.713 \\
\hline- & $\geq 5$ & $0.94(0.50-1.76)$ & 0.845 & $0.59(0.27-1.25)$ & 0.169 \\
\hline \multicolumn{6}{|c|}{ Polypharmacy } \\
\hline- & $0-4$ drugs & 1.00 & & 1.00 & \\
\hline- & $5-9$ drugs & $1.16(0.48-2.80)$ & 0.735 & $1.64(0.57-4.68)$ & 0.357 \\
\hline- & $\geq 10$ drugs & $2.59(1.07-6.28)$ & $0.034^{*}$ & $4.04(1.29-12.63)$ & $0.016^{*}$ \\
\hline \multicolumn{6}{|c|}{ Nutritional impairment } \\
\hline- & No & 1.00 & & 1.00 & \\
\hline- & Yes & $1.96(1.15-3.33)$ & $0.013 *$ & $2.71(1.45-5.10)$ & $0.002 *$ \\
\hline \multicolumn{6}{|c|}{ PIP of ADs } \\
\hline- & No & 1.00 & & 1.00 & \\
\hline- & Yes & $1.64(1.02-2.63)$ & $0.040^{*}$ & $2.30(1.28-4.12)$ & $0.005^{*}$ \\
\hline \multicolumn{6}{|c|}{$\begin{array}{l}\text { Depressive syndrome (score on the } 15 \text {-item } \\
\text { GDS) }\end{array}$} \\
\hline- & $<5$ & 1.00 & & 1.00 & \\
\hline - & $5-10$ & $1.67(0.99-2.79)$ & 0.053 & $0.68(0.36-1.27)$ & 0.227 \\
\hline - & $>10$ & $1.26(0.56-2.83)$ & 0.576 & $0.41(0.13-1.33)$ & 0.136 \\
\hline
\end{tabular}

Abbreviations: ADL = Activities of daily living; GDS = Geriatric Depression Scale; HR = Hazard Ratio; IADL = Instrumental Activities of Daily Living; MMSE = Mini Mental State Evaluation; PIP of ADs = Potentially Inappropriate Prescription of Antidepressants.

* $\mathrm{p}<0.05$ 